\title{
IMPLICATION ON FIXED-BED-CATALYTIC-REACTOR DESIGN WHEN CONSIDERING INTRAPARTICLE MATERIAL BALANCE AT MICROSCALE
}

\author{
KLAUS SERNY ${ }^{1 *}$, MILEXI PACHECO ${ }^{2}$ \\ ${ }^{1}$ Computational Chemistry Laboratory, Venezuelan Institute of Scientific Research, Altos \\ de Pipe, 1204, Miranda, Venezuela \\ ${ }^{2}$ Polymer Laboratory, Venezuelan Institute of Scientific Research, Altos de Pipe, 1204, \\ Miranda, Venezuela
}

\begin{abstract}
The integration between catalytic chemistry and reaction engineering fields generate more efficient catalytic reactor designs whereby the conventional design strategies should be changed. This work evaluated the implications on preliminary fixed bed catalytic reactor design and its associated basic cost from bench-scale when it is considered the material balance at microscale under a deterministic model accompanied with heuristic considerations on equipment design showing that understanding chemical reaction engineering is key to design of more efficient and economical industrial processes (decrease in $50 \%$ of equipment sizing and $40 \%$ of the equipment cost for this study).
\end{abstract}

Keywords: design, reactor, microkinetic, microscale, diffusion, size, cost

\section{INTRODUCTION}

A suitable industrial catalytic reactor design is based essentially, on finding the optimal equipment size that satisfies chemical reaction requirements with special attention to desired product conversion to minimize cost and maximize profit [1]. This is an active area of chemical engineering research that is focused on the efficient use of raw materials, resources, and an effective reduction of equipment size. In this way, maximum yield and selectivity at the lowest possible cost of equipping manufacturing are achieved [2].

Catalytic processes play important roles in petroleum refining, chemical processing, and environmental preservation. Conventional design strategies for the catalytic reactor are based mostly on reaction kinetic information with noting or minimum information coming from catalytic chemistry. New strategies for design could be generated by carrying out the integration between catalytic chemistry and reaction engineering fields [3]. It is possible to generate more efficient catalytic reactor designs (macroscale) through the use of relevant information from transport phenomena (macro kinetic) and chemical phenomena (microkinetic).

Conventionally, the conceptual design of catalytic reactors is based on material and energy balance throughout the knowledge of variables governing its operation, such as flowrate, composition in reactor inlet and outlet, conversion to desired products, temperature, pressure, and taking the reaction rate as an overall parameter. This last parameter is coming from laboratory tests on chemical reaction conditions and can be used in mathematics models like the pseudo-homogeneous model, without discriminating information about diffusional transport, chemical reactions, and catalytic species whereby it tends to be closer to overall production rate. Also, the reaction rate is a function of the species concentration that changes through the reactor length. Therefore, this rate is taking as an average.

\footnotetext{
* Corresponding author, email kserny@gmail.com

(C) 2020 Alma Mater Publishing House
} 
To move along the scale-up process to optimal equipment size, theoretical models, laboratory tests on chemical reactions, and internal diffusional transport parameters are prior information for heterogeneous catalytic reaction behaviors in heterogeneous systems. This has been part of the traditional discipline of chemical engineering [4]. The scale-up is divided into two blocks. The first refers to the body of knowledge which analyzes and studies complex systems from the fundamental chemical and physical processes. The second corresponds to engineering; it uses the information from the previous block to design and builds industrial plants [5]. Due to economic, environmental, and security needs, reactors design requires optimization of several parameters. The catalytic reactor design needs the knowledge of reaction rates and selectivity, as a function of the operating conditions, with special emphasis on the use of intrinsic velocities for the kinetics. Without it, the design is risky, not well substantiated and with high uncertainty in its operation [6].

The overall production rate in a catalytic process is responsible for changes in concentration of interest compound on time where intimate relationships between the diffusion transport and the chemical conversion in catalyst play an important role. The effect of catalyst depends on its structure itself and conversion rates in each catalyst particle (microkinetic) that is knowledge as intrinsic velocities, defined from intrinsic reactivity and velocities of molecular exchange between the particle and its surroundings [7].

In the catalytic system, diffusional transport and chemical reaction usually come in series. However, intraparticle diffusion and chemical transformation (adsorption, surface reaction, and desorption) take place in different sites. Consequently, the phenomena of internal diffusional transport, as well as chemical reactions, must be considered. General steps occurring when a fluid is contacting with porous solid can illustrate in Figure 1, namely: 1) External diffusion of the reactants from bulk fluid to the solid surface; 2) Internal diffusion of the reactants in the pore; 3) Adsorption of the reactants on the surface sites; 4) Chemical reaction; 5) Desorption of products from the surfaceactive site; 6) Diffusion of products toward the pore mouth; 7) Diffusion of products from the solid surface to the bulk fluid. This scheme agrees with that stated by Dittmeyer and Emig, 2008 [8], and Fogler, 2016 [9].

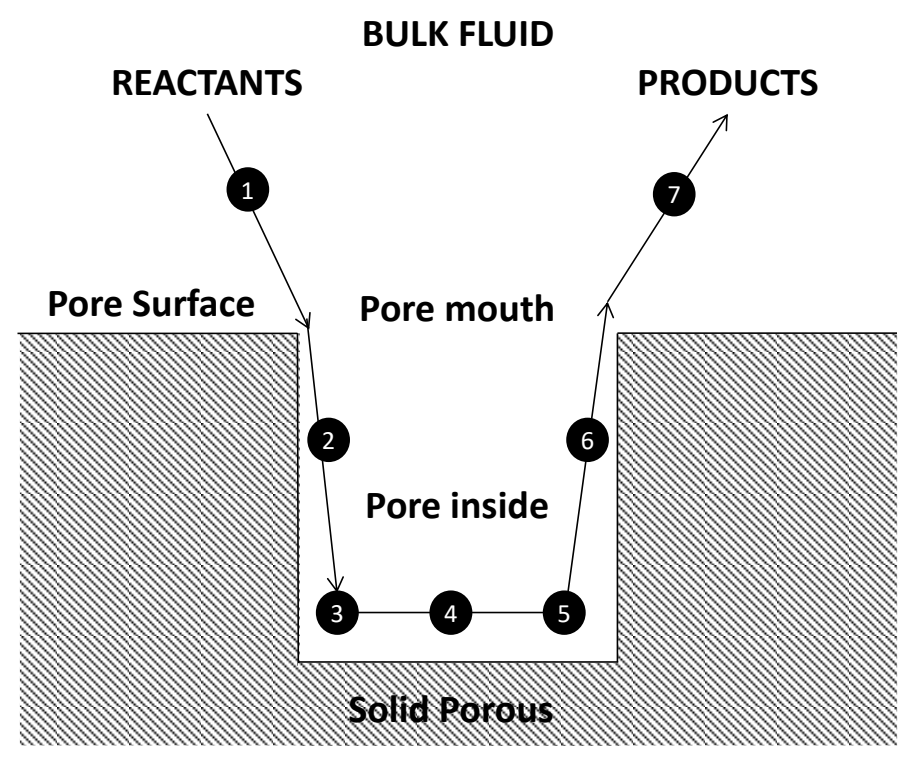

Fig. 1. A general scheme of steps that occur in a heterogeneous catalytic process: (1)-External diffusion of reactants from the bulk fluid to the solid surface; (2)-Diffusion of reactants into the pore; (3)-Adsorption of reactants on the surface sites; (4)-Catalytic reaction; (5)-Desorption of products from the surface-active site; (6)Diffusion of products toward the pore mouth; (7)-Product diffusions from the solid surface to the bulk fluid.

Such as it is observed in Figure 1, both phenomena are occurring, and each one should have a contribution to the overall production rate. Therefore, it is important taking them into account for a better understanding of the kinetic behavior of species in a catalytic process and in this way, optimizing the design of the catalytic reactor [10].

This approach is achieved through the study of the total conversion of the reactants and products where steps 1 and 7 of Figure 1 are verified and the stages inside the particle can be represented employing a first-order velocity equation. Since the reaction is irreversible, the concentration of products does not affect the rate, so the process 
can be described only with two stages (the transport of reactants to the surface of the particle and the reaction rate within the particle). Since these two rates in steady state are equal, then the disappearance rate of the reactants can be expressed with either of the two stages mentioned above [11].

Diffusion and heterogeneous catalytic reaction supported on porous catalysts have been intensively researched for over half a century and it is still interested in the investigations on them [12]. Many unexpected nonlinear phenomena in the zeolites diffusion have been reported in the literature, like the shape selectivity, activation energies for diffusion, window effects, the drive of selectivity by pore length, effect of occupancy, etc. [13] which will take high relevance in future studies. Particularly, the study and the commercial exploitation in new industrial technologies based on zeolite knowledge is the main challenge to optimize processes and equipment design [14].

The understanding of chemical reaction engineering is key to optimal-economically, environmental-friendly, and energy-efficiently processes with choosing the right chemical transformation with the right catalyst, and the right reactor type with its right scale up to commercial production [15]. Thus, the importance of knowledge and understanding of this heterogeneous system (process variables, catalytic species, chemical reaction, and diffusional transport) it is fundamental to optimize the design of the catalytic reactor to reduce the equipment size. This will impact on the construction costs for the units in the catalytic process.

Additionally, the reactor typically represents between $5 \%$ and $15 \%$ of capital and operating costs of the plant, thus, its right selection and design will determine the number and load on pre reactor and post reactor separation units and dictates the cost of the whole process [15].

Traditionally, reactor design has followed heuristic rules [16], one of them is the two-thirds law for economic of scale based on simple topology and geometry that follows a predictable scaling law. The individual reactor scale follows a scaling law of cylinder using the reaction zone defined at the resident time. Stark argues that for the design of chemical conversion processes the first interpretation comes from the downscaling unit allowing a more holistic approach improves chemical processing efficiency while decreasing equipment size, and waste.

Knowledge of the rate of a catalytic reaction and its selectivity as a function of the process conditions and reactant concentrations is essential for the application of the catalyst in a commercial reactor. More specifically, the kinetic of the reaction is required in the form of a mathematical rate expression that can be used to reliably translate laboratory and pilot-scale data into the design of a commercial-scale unit. The importance of a kinetic reaction is that the rate and selectivity of a reaction determine the size of the catalytic reactor for a given overall production rate [6]. Strive for intrinsic kinetics rather than apparent kinetics where the transport effects and intrinsic kinetics are lumped is needed to improve the efficiency accuracy of kinetic modeling [16], and also improves the reliability and accuracy of the model when extrapolated to the following scaling-up phases into catalytic reactor design.

This work aims to evaluate the implications on preliminary fixed bed catalytic reactor design and its associated basic cost using information coming from when is considered the material balance at microscale proposing an approximation on mathematical expression that permit to estimate the intrinsic reaction rate, as a starting point, to reliably translate bench scale data that can be used for the design in the following stages of scaling up, and taking relevant information from catalyst such as characteristic particle size, internal diffusion, specific surface area and density in the heterogeneous catalytic system under a deterministic model accompanied with heuristic considerations on equipment design.

\section{MATHEMATICAL MODELING}

From the engineering point of view, the focus of conventional catalytic reactor design is to calculate the reactor diameter and length after having calculated the volume of the solid (catalyst). An elemental scheme of material balance in a cut of a plug flow reactor is shown in Figure 2.

From this scheme, the following steady-state material balance equation appears:

$$
\left[F_{A}\right]_{\text {in }}=\left[F_{A}\left(1-X_{A}\right)\right]_{o u t}+V_{S}\left(-v_{A o v}\right)
$$

where $\left(-v_{A o v}\right)$ is the overall reaction rate (moles of $\mathrm{A} \mathrm{x} \mathrm{m}^{-3}$ cat $\left.\mathrm{x} \mathrm{s}^{-1}\right), F_{A}$ is the mass flow rate (moles de $\mathrm{A} / \mathrm{s}$ ), $X_{A}$ is the conversion degree of $A$ species, and $V_{s}$ corresponds to the volume of solid catalyst $\left(\mathrm{m}^{3}\right)$ [17]. The equation (1) 
is indicated because the overall reaction rate from experimental data at bench scale plant should correspond to the reaction rate without including diffusion and heat transfer effects (physical processes) [11]. The first step in the logical procedure of reactor design is to obtain an adequate mathematical expression for the reaction rate which could considerer an intrinsic reaction rate $\left(v_{\text {Aint }}\right)$.

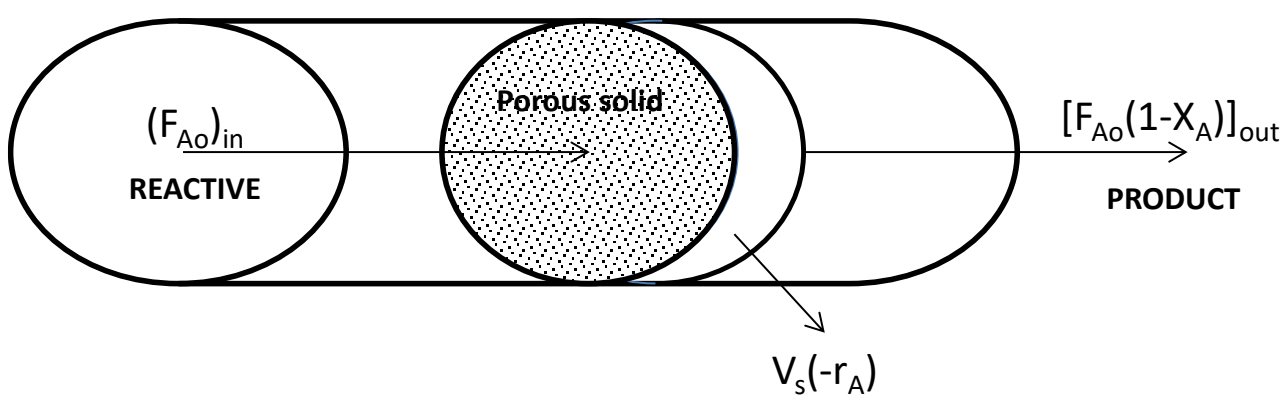

Fig. 2. Material balance in an elemental cut of plug flow reactor with catalyst: $F_{\mathrm{A}_{0}}$ is the mass flow rate of species, $X_{A}$ is conversion degree of $A$ species and $V_{S}\left(-v_{A}\right)$ corresponds to the flow rate of converted of $A$ species.

Assuming for the preliminary reactor design that the reactor volume $\left(V_{r}\right)$ is equal to $V_{S}$ the following mathematical expression is obtained after handling and ordering the equation (1),

$$
V_{r}=\frac{F_{A}\left(X_{A}\right)}{\left(-v_{A o v}\right)}
$$

Note that mass flow rate, conversion, and overall reaction rate are parameters that come from laboratory tests. Also, the conversion and the intrinsic reaction rate depend on the catalyst nature and chemical process. To consider information from microscale, an elemental section inside of catalyst pores is shown in Figure 3. Here a first-order kinetic reaction is assumed.

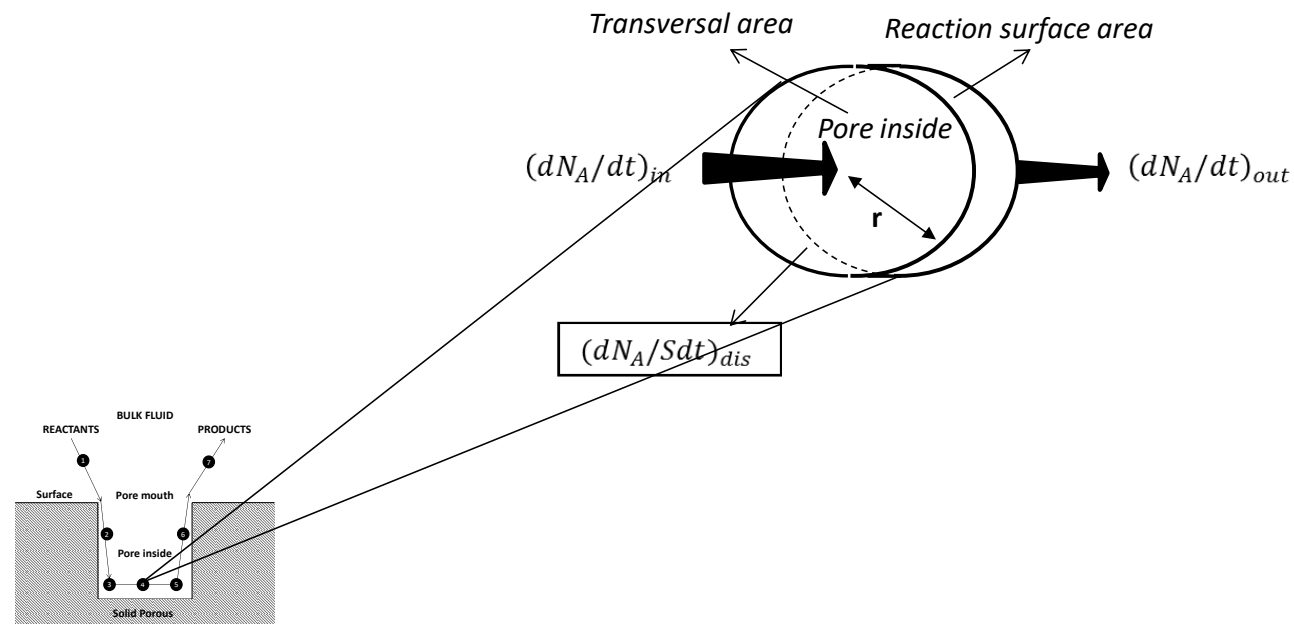

Fig. 3. Material balance in an elemental section inside of catalyst pores. $\left(\frac{d N_{A}}{d t}\right)$ is the molar flow rate of A species, and $\left(\frac{d N_{A}}{S d t}\right)$ is the disappearance rate of $A$ per unit of reaction surface $(S)$.

The disappearance rate of $A$ per unit of reaction surface $(S)$ is given by:

$$
\left(\frac{d N_{A}}{S d t}\right)_{d i s}=\left(-v_{\text {Aint }}\right)
$$

Thus, from a steady-state material balance of $A$ species, the number of mols $\left(N_{A}\right)$ in an elemental pore $\operatorname{section}(\Delta l)$ takes the following mathematical expression [17]. 


$$
\left(\frac{d N_{A}}{d t}\right)_{i n}=\left(\frac{d N_{A}}{d t}\right)_{o u t}+\left(\frac{d N_{A}}{S d t}\right)_{d i s}
$$

The diffusional transport rate, as has been proposed by several authors $[17,11]$ is assumed to be governed by the first law of Fick:

$$
\begin{aligned}
& \left(\frac{d N_{A}}{d t}\right)_{\text {in }}=\pi r^{2} D\left(\frac{d C_{A}}{d l}\right)_{\text {in }} \\
& \left(\frac{d N_{A}}{d t}\right)_{\text {out }}=\pi r^{2} D\left(\frac{d C_{A}}{d l}\right)_{\text {out }}
\end{aligned}
$$

Then, the equation (4) for a steady state can be written as,

$$
\pi r^{2} D\left(\frac{d C_{A}}{d l}\right)_{i n}=\pi r^{2} D\left(\frac{d C_{A}}{d l}\right)_{o u t}+2 \pi r \Delta l\left(-v_{\text {Aint }}\right)
$$

where $D$ corresponds to the diffusion coefficient $\left(\mathrm{m}^{2} / \mathrm{s}\right), C_{A}$ is the concentration of species $A\left(\mathrm{~mol} / \mathrm{m}^{3}\right)$, being this equation consisting of its units. The equation (7) can be rewritten as follows:

$$
\frac{r}{2} D \frac{\left(\frac{d C_{A}}{d l}\right)_{i n}-\left(\frac{d C_{A}}{d l}\right)_{o u t}}{\Delta l}=\left(-v_{\text {Aint }}\right)
$$

Knowing that $\left(-v_{\text {Aint }}\right)=k C_{A}$ for a first-order reaction, where $k$ is a kinetic constant, it is possible to write the equation (8) as follows:

$$
D \frac{\left(\frac{d C_{A}}{d l}\right) l=0-\left(\frac{d C_{A}}{d l}\right)_{l=l_{p}}}{l_{p}}=\left(-v_{A i n t}\right)
$$

where the term $\frac{2}{r}$ has been incorporated into the kinetic constant, being consistent to a kinetic equation of first order where $k$ has units $\frac{m}{s}$ and $\left(-v_{\text {Aint }}\right)$ in $\frac{m o l}{s m^{2}}$

The numerical solution for equation (9) is taking account of the boundary conditions. First, at the pore entrance $\left(\frac{d C_{A}}{d l}\right)_{i n}=C_{A}$ at $l=0$, since the transformation of species A has not yet begun into pore, where $C_{A}$ is the concentration of A species into overall fluid of feed at the pore surface, and second condition, $\left(\frac{d C_{A}}{d l}\right)_{\text {out }}=0$ at $l=l_{p},[17]$ leaving the equation $(9)$ as follow:

$$
D \frac{C_{A}}{l_{p}}=\left(-v_{\text {Aint }}\right)
$$

The equation (10) is under the exposed by Smith 1991 [11], which arguments that assuming a steady-state, kinetic equation of first order and irreversible reaction, thus, the molecular diffusion transport rate is equal to reaction rate depending on the diffusion coefficient, reactant concentration, and pore longitude.

Considering the elucidated equation at microscale to closest knowledge on reaction, it possible to do a steady-state material balance in plug flow reactor filled with a catalyst based on overall reaction surface area $\left(S_{r}\right)$ being that for multiphase systems (fluid-solid) the reactions take place only when reactants come in contact with the surface of particle.

The element of the volume on which $\left(-v_{\text {Aint }}\right)$ is based must include at least one catalytic particle; otherwise, it is not possible to consider the basic effects in the interface. There is no obstacle; this rate is used as an expression applicable to a volume differential, that is, as local rate. This is an approximation that originates when considering the discrete nature of a bed of catalytic particles as if it were continuous. It is a necessary approximation since it is not yet possible to consider the variations in mass transfer concerning the surface position of a single catalytic particle in a fixed bed. Due to this, average values are used in the fixed bed for the formulation of rate [11].

In these situations, the surface area available for the reaction is a better measure of the extent of the reaction system, and the reaction rate assumes the dimensions of $\mathrm{mol} /\left(\mathrm{m}^{2} \mathrm{~s}\right)[18]$ obtaining the following equation 


$$
\left[F_{A 0}\right]_{\text {in }}=\left[F_{A 0}\left(1-X_{A}\right)\right]_{o u t}+S_{r}\left(-v_{\text {Aint }}\right)
$$

Substituting the equation (10) into (11) it is obtained a general mathematical expression which could be used to calculate $S_{r}$ related to the catalytic reactor:

$$
S_{r}=F_{A} X_{A} /\left(D \frac{C_{A}}{l_{p}}\right)
$$

The proposed model (equation (12)) considers the following assumptions:

- Constant temperature;

- Constant concentration gradient;

- Concentration change only occurs in the characteristic particle size $\left(l_{p}\right)$;

- Diffusion coefficient is constant;

- Catalytic particles are structurally identical;

- External diffusional transport resistance is neglected;

- Adiabatic system;

- Radial flux is neglected.

The analysis on the importance of considering the intrinsic rate of a reaction in the development of metaheuristic models, such as the equation (12), is in accordance with the exposed by Serny et al. 2015 [19], where these authors have built a mathematical model from diffusional transport considerations for a fixed bed catalytic reactor design.

As mentioned, from the engineering point of view, the focus of the catalytic reactor design is to calculate its diameter and length. For this, it is required to know the reaction volume $\left(V_{r}\right)$ that can be obtained by dividing $S_{r}$ by the product of the catalyst specific surface area $\left(S A_{\text {cat }}\left[\frac{\mathrm{cm}^{2}}{\mathrm{~g}}\right]\right)$ with the catalyst density $\left(\rho_{\text {cat }}\left[\frac{\mathrm{g}}{\mathrm{cm}}\right]\right)$ obtained at meso level. Thus, the following equation results,

$$
V_{r}=S_{r} / S A_{\text {cat }} \rho_{\text {cat }}
$$

In order to achieve estimations, for a real operational behaviour in the catalytic process, it is necessary to incorporate heuristics considerations in accompaniment of the deterministic models that have been developed previously with intention of obtain the adequate reactor geometry, such as its length and diameter by means of standard equation of a cylinder $\left(V_{r}=\pi /{ }_{4} D_{r}{ }^{2} L\right)$ where $D_{r}$ and $L$ are diameter $(m)$ and length $(m)$ of the reactor, respectively.

Usually, it is required design criteria from $\left(\mathrm{L} / \mathrm{D}_{\mathrm{r}}\right)$ heuristics basics in engineering processes. The best practice for engineering design reports as criteria an $\left(\mathrm{L} / \mathrm{D}_{\mathrm{r}}\right)$ between 2.5 to 5 , suggesting a value of 3 , as the first approximation in the calculation of this relationship [20,21].

\section{METHODOLOGY}

The conventionally used methodology for sizing and costs analysis related to industrial processes has its basement in the best engineering practices of projects and they are shown as logical sequence steps in the frame of the scaling-up phase, as indicated as follows.

In this work, the study scale is in a bench plant on conceptual design taking experimental data from $[19,22,23$, 24] that relate all of them with a fixed bed catalytic reactor using a porous solids (catalyst). These authors have considered and discussed the influence of diffusion parameters on the reactor design. In this way, the data collection will be completed as a first step. With the previous information, it is possible to estimate the equipment basic sizing on conceptual design criteria, as a second step. The associated cost to conceptual design is defined as class IV, where it could be estimated with the information corresponding to material costs in the main equipment (catalytic reactor), as a third step. 
The total manufacture cost could be a function of initial capital investment, costs of utilities, operating labor, raw materials, water treatment, etc. According to Chebbi, 2014 [1], the cost minimization methodology is related to the reactor size whereby for the present work the objective is cost minimization taking into account the minimization of the total reactor volume, excluding the other costs deferring to future investigations.

In the final section, a comparative analysis (equipment sizing and associated cost) between the proposed and conventional model, on the scaling-up phase in conceptual design, is presented.

\section{RESULTS AND DISCUSSION}

In order to quantify the diffusional transport effect when it is considered on the design of fixed bed catalytic reactors, the mathematical equations (2), (12), and (13) were operated with the information from Table 1 to obtain the required reactor volume and subsequent basic sizing of equipment obtained from Previous works.

For the calculation of the overall reaction surface with equation (12), it was considered the following assumptions: - The chemical reaction occurs only on pore surface area once by pore;

- All catalyst particles are identical into the system;

- The occurrence of the chemical reaction in a catalyst particle is identical for all the catalyst particles that make up the packaging of the reactor.

Additionally, it was required to estimate characteristic particle size $\left(l_{p}\right)$ which depends on the particle shape. For the collected experimental data from the above-mentioned works, it is considered the expressions for a sphere particle $\left(l_{p}=r / 3\right)$ and for a cylindrical particle $\left(l_{p}=r / 2\right)$, where $\mathbf{r}$ is the particle radius [17]. Thus, the obtained values of effective pore length were $0.075 \mathrm{~cm}, 0.15 \mathrm{~cm}$, and $0.02 \mathrm{~cm}$ respecting to reference [19, 22, 23, 24] using the half of the particle diameter and particle shape (Table 1), Using equations (12), and (13) and the engineering design criteria $\left(L / D_{r}\right)$ value of 3 , the reaction surface and volume, diameter, and length of reactors are showed in the Table 2 .

The complexity of the flow paths around an individual catalyst particle suspended in the flow of a fluid is considerable and becomes complicated when combined with interactions between them. It is therefore that, mass average coefficients and average rates are considered with the use of concentration measurements in the laboratory allowing obtain an intrinsic rate equation related to the overall fluid conditions [11].

Table 1. Information related to the fixed bed catalytic reactors on bench scale.

\begin{tabular}{|c|c|c|c|}
\hline \multirow[b]{2}{*}{ Data } & \multicolumn{3}{|c|}{ References } \\
\hline & [19] & {$[22,23]$} & {$[24]$} \\
\hline Reactor volume, $\mathrm{cm}^{3}$ & 15 & 105.84 & 173.09 \\
\hline Reactor diameter, $\mathrm{cm}$ & 1.85 & 2.12 & 2.10 \\
\hline Reactor length, cm & 5.56 & 30.00 & 50.00 \\
\hline Feed rate, $\mathrm{mol} / \mathrm{s}$ & $1.50 \mathrm{E}-04$ & $9.83 \mathrm{E}-01$ & $4.66 \mathrm{E}-03$ \\
\hline Conversion, adim & 0.21 & 0.85 & 0.85 \\
\hline Diffusion coefficient, $\mathrm{cm}^{2} / \mathrm{s}$ & $2 \mathrm{E}-11$ & $4.63 \mathrm{E}-03$ & 4.60E-04 \\
\hline Initial concentration, $\mathrm{mol} / \mathrm{cm}^{3}$ & $2.00 \mathrm{E}-07$ & $2.20 \mathrm{E}-06$ & $2.40 \mathrm{E}-03$ \\
\hline Particle diameter, $\mathrm{cm}$ & $1.2 \mathrm{E}-01$ & $4.5 \mathrm{E}-01$ & $3.0 \mathrm{E}-01$ \\
\hline Particle shape & spherical & spherical & Cylindrical \\
\hline Particle specific surface area, $\mathrm{cm}^{2} / \mathrm{g}$ & $3.8 \mathrm{E}+06$ & $4.3 \mathrm{E}+04$ & $4.3 \mathrm{E}+04$ \\
\hline Particle density, $\mathrm{g} / \mathrm{cm}^{3}$ & 0.54 & 2.84 & 3.00 \\
\hline
\end{tabular}


Table 2. Estimated sizing of equipment using the proposed model design.

\begin{tabular}{|l|c|c|c|}
\cline { 2 - 4 } \multicolumn{1}{c|}{} & \multicolumn{3}{c|}{ References } \\
\cline { 2 - 4 } \multicolumn{1}{c|}{} & {$[19]$} & {$[22,23]$} & $6.46 \mathrm{E}+06$ \\
\hline Reaction surface, $\mathrm{cm}^{2}$ & $1.31 \mathrm{E}+07$ & $6.16 \mathrm{E}+06$ & 50.09 \\
\hline Reactor volume, $\mathrm{cm}^{3}$ & 6.36 & 50.46 & 2.77 \\
\hline Reactor diameter, $\mathrm{cm}$ & 1.39 & 2.78 & 8.31 \\
\hline
\end{tabular}

From the engineering point of view, it is important to associate the designed equipment size with an estimated cost to its construction whereby were used models from "manual of cost estimate and equipment profitability" establishing as parameters for calculation the showed information in Table 3.

The expression used for cost estimate is:

$$
E C=\left(M_{C}\right)\left(M_{W}\right)\left(M_{f}\right)
$$

where $E C=$ Equipment Cost (USD), $M_{C}=$ material cost USD/ton), $M_{W}=$ material weight (ton), and $M_{f}=$ material factor.

Estimated material weight is preceded for calculated equipment material surface $\left(S_{M a t}\right)$ using the expression (15) by considers a cylindrical shape,

$$
S_{\text {Mat }}=\pi D_{r} L+\frac{\pi D_{r}^{2}}{2}
$$

where $\left(L / D_{r}\right)$ ratio is 3 as the assumed value of the design criteria mentioned above. Multiplying $S_{\text {Mat }}$ with the material thickness from Table III, the material volume $\left(V_{M a t}\right)$ is calculated. On the other hand, the material weight $\left(M_{W}\right)$ is obtained by-product between $\left(V_{\text {Mat }}\right)$, thickness, and material density $\left(\rho_{\text {Mat }}\right)$ from Table 3.

\begin{tabular}{|c|c|}
\hline Parameter & Value \\
\hline Material & 304 stainless steel (304SS) \\
\hline 304SS density, $\mathrm{kg} / \mathrm{m}^{3}$ & 7,780 \\
\hline $304 S S$ cost ${ }^{\mathrm{a}}$ USD/tonne & $2,379^{\mathrm{c}}$ \\
\hline Design criteria L/D & 3 \\
\hline Design minimum thickness ${ }^{\mathrm{b}}, \mathrm{mm}$ & 5 \\
\hline 304SS material factor ${ }^{\mathrm{b}}$, adim & 2.8 \\
\hline
\end{tabular}

Table 3. Information to estimate associated costs on conceptual design.

${ }^{\mathrm{a}} \mathrm{www} . w o r l d s t e e l p r i c e s . c o m . ~{ }^{b}$ Manual of cost estimate and equipment profitability. ${ }^{\mathrm{c}} 2017$ year.

Associated costs and sizing for catalytic reactor calculated by the conventional design model and the proposed are showed in Table 4. It reveals a reduction in the equipment sizing and cost favoring the use of the proposed model considering the diffusional transport in the catalytic reactor design.

Additionally, lower consumption of catalyst per initial charge could be estimated based on the reactor volume reduction maintaining selectivity and conversion of the catalytic reaction. Also, it is inferred lower power consumption due to the process would operate under more efficient conditions in the heterogeneous system. These parameters added advantages in incorporating diffusional transport parameters in the design of catalytic reactors.

Finally, a table of advantages between the conventional model and the proposed in the design of the catalytic reactor is presented in Table 5. 
Table 4. Comparison between conventional (CONV) and this work design, considering, size, and cost, in bench scale.

\begin{tabular}{|c|c|c|c|c|c|c|}
\hline \multirow{2}{*}{ References } & Model & $\begin{array}{c}\text { Reactor } \\
\text { Volume, } \mathbf{c m}^{3}\end{array}$ & $\begin{array}{c}\text { Reactor } \\
\text { Diameter, } \mathbf{~ m}\end{array}$ & $\begin{array}{c}\text { Reactor } \\
\text { Length, cm }\end{array}$ & $\begin{array}{c}\text { 304SS material } \\
\text { volume, } \mathbf{c m}^{\mathbf{3}}\end{array}$ & Cost, USD \\
\hline \multirow{2}{*}[19]{} & CONV & 15 & 1.85 & 5.56 & 18.88 & $1,176,621$ \\
\cline { 2 - 7 } & This work & 6.36 & 1.39 & 4.18 & 10.65 & 663,960 \\
\hline \multirow{2}{*}[22,23]{} & CONV & 105.84 & 2.12 & 30.00 & 103.38 & $6,443,064$ \\
\cline { 2 - 7 } & This work & 50.46 & 2.78 & 8.33 & 42.38 & $2,641,255$ \\
\hline \multirow{2}{*}[24]{} & CONV & 173.09 & 2.10 & 50.00 & 168.31 & $10,489,872$ \\
\cline { 2 - 7 } & This work & 50.09 & 2.77 & 8.31 & 42.17 & $2,628,474$ \\
\hline
\end{tabular}

Table 5. Advantages of the approach in this work concerning the conventional method (CM).

\begin{tabular}{|l|l|}
\hline \multicolumn{1}{|c|}{ Considerations } & \multicolumn{1}{c|}{ Proposed design advantages } \\
\hline Sizing & Over $50 \%$ smaller than CM \\
Equipment cost & Over $40 \%$ smaller than CM \\
Catalyst cost & Over $50 \%$ less than CM \\
Power consumption & Reduction of at least $1 / 3$ less than CM \\
Initial catalyst consumption & Reduction of at least $50 \%$ \\
\hline
\end{tabular}

The joint design of catalyst and reactor on the understanding of transport processes and chemical phenomena, where the intrinsic reactivity and physical parameters of the catalyst plays an important role in the reaction kinetics $[15,25]$ where ongoing research to sustainable design should include the development of multiscale systems approaches that address the micro-meso-macro scales associated with the chemical process industry [26]. This will allow exploring modes of operation and novel designs in heterogeneous systems, opening the possibility to computational catalysis as an advantageous and powerful tool against experimentation establishing parameters of commercial processes at a lower cost and better use of energy for the process.

\section{CONCLUSIONS}

Considering a steady-state material balance at porous level (microscale) was possible calculated an intrinsic reaction rate belonging of the relationship between the chemical reaction and the involved catalytic species as an approach to intraparticle diffusional transport from experimental tests in the bench-scale meaning a decrease of the estimated reactor size. Note that the reactor volume is inversely proportional to the reaction rate. It is showed that the developments of multiscale approaches that address the micro-meso-macro are very important in the reactor design.

In the conventional method for catalytic reactor design an overall reaction rate is used which represents a production rate without discriminating intrinsic reaction rate and mass transport rates, this may explain the fact that the conventional reactor sizing is overestimated for the scaling-up phase.

The present study shows that understanding chemical reaction engineering is key to design of more efficient and economical industrial processes using the material balance in porous at the microscale, as well as, properties of catalyst achieving a more optimal design on fixed-bed-catalytic-reactor. This has implications of a decrease in the equipment size, a decrease of the reactor construction costs, and the use of more efficient energy resources.

The inclusion of other effects will be considered as corrections in future works, such as interparticle diffusion, effectiveness factor, secondary reactions, and deactivation of the catalyst. These effects would be important in the scaling-up phase when the reactor is designed.

The advantages of using the proposed model over the conventional in the design of the catalytic reactor of the fixed bed have shown a decrease in $50 \%$ of equipment sizing and $40 \%$ of the equipment cost for conceptual design for this study. 


\section{REFERENCES}

[1] Chebbi, R., Optimizing reactors selection and sequencing: minimum cost versus minimum volume, Chinese Journal of Chemical Engineering, vol. 22, no. 6, 2014, p. 651-656.

[2] Zhou, W., Manousiouthakis, V., Global capital/total annualized cost minimization of homogeneous and isothermal reactor network, Industrial and Engineering Chemistry Research, vol. 47, 2008, p. 3771-378

[3] Igarachi, A., Catalytic reaction engineering toward green chemical processes, Journal of Chemical Engineering of Japan, vol. 38, no. 10, 2005, p. 779-784.

[4] Schuurman, Y., Aspect of kinetic modeling of fixed bed reactor, Catalysis Today, vol. 138, 2008, p. 15-20.

[5] Wintermantel, K., Process and product engineering - achievements, present and future challenges, Chemical Engineering Science, vol. 54, 1999, p. 1601-1620.

[6] Berger, R., Stitt, E., Marin, B., Kapteijn, F., Moulijn, J., Chemical reaction kinetics in practice, Eurokin, vol. 5 , no. 1, 2001, p. 30-31.

[7] Kärger, J., Vasenkov, S., Quantitation of diffusion in zeolite catalysts, Microporous and Mesoporous Materials, vol. 85, 2005, p. 195-206.

[8] Dittmeyer, R., Emig, G., Simultaneous heat and mass transfer and chemical reaction, Handbook of Heterogeneous Catalysis, Ed. Wiley-VCH Verlag GmbH and Co KGaA, 2008.

[9] Fogler, H., Elements of chemical reaction engineering, 5th. Ed. Prentice-Hall. New Jersey. 2016

[10]. Marshall, J., Weisz, D., Determination of diffusivities in catalyst particles, Journal of Catalysis, vol. III, 1998, p. 460-463.

[11] Smith, J.M., Chemical engineering kinetics, 6 edition, Ed. McGraw-Hill, 1991.

[12] Haynes, H., Evaluation of catalyst effective diffusivity, Catalysis Reviews Science and Engineering, vol. 30, no. 4, 1998, p. 563-627.

[13] Wei, J., Nonlinear phenomena in zeolite diffusion and reaction, Industrial and Engineering Chemistry Research, vol. 33, 1994, p. 2467-2472.

[14] Flanigen, E., Molecular sieve zeolite technology - the first twenty-five tears, Pure and Applied Chemistry, vol. 52, 1998, p. 2191 - 2211.

[15] Dudukovic, M., Reaction engineering: status and future challenges, Chemical Engineering Science, vol. 65 , 2010, p. 3-11.

[16] Stark, A., Manufactured chemistry: rethinking unit operation design in the age of additive manufacturing, AIChE Journal, vol. 64, 2018, p. 1162 - 1173.

[17] Levespiel, O., Engineering of chemical reactions, 3rd. Ed. John Wiley and Sons, New York. 2006.

[18] Rota, R., Microkinetics versus macro kinetics: the role of transport phenomena in determining reaction rates, Fundamental of Chemistry, Unesco-EOLSS, 2009. p. 195-233.

[19] Serny, K., Baricelli, P., Pacheco, M., Melean, L., Rosales, M., Catalytic cracking of pentenes in MFI zeolite: Activation energy and reactor volume decrease, International Journal of English Research, vol. 4, no. 12, 2015 , p. 652-656.

[20] Anaya, A., Alarid, J., Diez, G., Garcia, L., Alejandro, M., Sierra, J., Heuristics rules for process equipment, Chemical Engineering, Ed. Mcgraw Hill, 2006.

[21] Walas, S., Heuristics in chemical - chemical process equipment selection and design engineering. Ed. Butterworth-Heinemann, 2002.

[22] Rodrigues, A.E., Ahn, B., Zoulalian, A., Intraparticle-forced convection effect in catalyst diffusivity measurements and reactor design, AlChE Journal, vol. 28, no. 4, 1982, p. 541-546.

[23] Ahn, B., Zoulalian, A., Smith, J.M., Axial dispersion in packed beds with large wall effect, AlChE Journal, vol. 32 , no. 1,1986 , p. 170-174

[24] Dong, Y., Keil, F., Korup, O., Rosowski, F., Horn, R., Effect of the catalyst pore structure on fixed bed reactor performance of partial oxidation of n-butane: A simulation study, Chemical Engineering Science, vol. 142, 2016, p. 299-309.

[25] Dudukovic, M., Trends in catalytic reaction engineering, Catalysis Today, vol. 48, 1999, p. 5-15.

[26] El-Halwagi, M., Sustainable design: a new frontier for chemical engineering, Journal of King Saud University - Engineering Science, vol, 30, no. 1, 2018. 